\title{
Acute appendicitis in children: How is it different than in adults?
}

Geha Raj Dahal, MS, PhD

Pediatric Surgery Unit, Department of General Surgery, Institute of Medicine, Tribhuvan University Teaching Hospital, Kathmandu, Nepal

Department of Pediatric Surgery, Grande International Hospital, Kathmandu, Nepal

Corresponding author

Geha R Dahal, MS, PhD

Email: geharajdahal@yahoo.com

Received 12 Dec 2018

Accepted 20 Dec 2018

\section{ABSTRACT}

Acute appendicitis is common in both children and adults. As children are different than adults in many aspects, the disease process, presentation, and outcome are different. Children have more complicated appendicitis. This article discusses the differences of acute appendicitis in children.

Key words: Acute appendicitis, children, adult

\section{Introduction}

'Children are not small adults'. This is a famous dictum in pediatric field. Every disease in children is different than adult in many aspects. Acute appendicitis is the most common emergency condition that requires surgery in children ${ }^{1}$. It is equally common in adults. Acute appendicitis itself is a great mimicker of many abdominal and few non abdominal pathology. Basic pathology, clinical presentation and management remains similar in children and adults, however there are many differences in epidemiology, pathogenesis, clinical presentations, complications, investigations and management. This article will focus on the specific issues of acute appendicitis in children.

\section{Epidemiology}

Appendicitis is rare in infants because the base of appendix is wide and funnel shaped. It becomes tubular like in adults by the age of 2 years ${ }^{2}$. Its incidence is 1-2 / 10000 children up to 4 years of age and sharply increases to approximately 25/ 10000 in the second decade of life ${ }^{1,3}$. Very few neonatal cases are reported in literature ${ }^{4}$. The incidence of appendicitis is low in small children but chances of perforation is higher in those small children. Age has direct relation with the stage of the disease.
The younger child has more complicated disease process ${ }^{5,6}$. Life time risk of appendicitis is $9 \%$ in male and $7 \%$ in female child. Peak incidence occurs in $10-19$ years of age ${ }^{1}$.

\section{Pathogenesis}

Appendicitis usually occurs due to obstruction of the lumen of appendix. Other contributing factors include dietary habit - low fiber, high refined sugar, and poor hygiene. But some epidemiological study does not support this ${ }^{7}$. Other important cause is ischemia due to vascular insult especially in neonates ${ }^{2}$. Small lumen of appendix is obstructed by enlarged lymphoid follicle. Lymphoid growth is high and peaks at 12 years of life ${ }^{8}$. Lymphoid hyperplasia occurs because of various inflammatory and infective conditions. The highest incidence of appendicitis corresponds to the highest lymphoid growth time ${ }^{9}$.

\section{Clinical features}

Infants and small children have less symptoms, and irritability may be the only symptom. Clinical suspicion is also less owing to fewer incidences. They often present with complicated appendicitis. The history in children is also less reliable ${ }^{10}$. Classical symptoms consist of periumbilical pain shifting to the right iliac fossa, nausea and 
vomiting with low grade fever. This is seen in less than $60 \%$ of children ${ }^{11}$. However abdominal pain, nausea and vomiting are prominent. Diagnosis of acute appendicitis should be reconsidered in the absence of these symptoms. A hungry child rarely has appendicitis. Pain abdomen and vomiting are also the usual symptoms of gastroenteritis. Symptomatically, these two entities can be difficult to distinguish.

Vomiting is the most frequent presenting symptom in child less than 3 years of age. Perforation is almost always present in these children ${ }^{12}$. They present with features of peritonitis, most commonly abdominal distension and tenderness. Diagnosis is often delayed because of non-specific symptoms. Pain always starts earlier than vomiting except in retrocaecal appendix where the tip is pointed upwards to the duodenum. Pain may be less because of position of appendix eg. retrocaecal, post ileal. It is the same as in adults. Significant diarrhea is less common except in long pelvic appendix which touches rectum. But diarrhea is more common in children than adults. It can create confusion with gastroenteritis. The duration of diarrhea is short as compared to gastroenteritis. High grade fever is not seen in uncomplicated appendicitis. Once child grows up, they can describe the symptoms well and pain abdomen remains the most important symptom.

Examination of children requires special skills and patience. Typical finding of tenderness and rebound tenderness is found only in older and cooperative children. Small children are uncooperative and they are often irritable and cry on touch. Children may not be able to localize the site of pain. Almost all children point to the umbilicus as the site of pain because it is the most prominent part of the abdomen. Classical rebound tenderness should not be elicited because it hurts the child and he/she may not cooperate in subsequent examination. It is done by asking to cough or jump lightly. A study by Becker et al. showed that $44 \%$ cases have 6 or more atypical symptoms ${ }^{13}$. Infants usually flex their legs over abdomen. Older children lie quietly on beds in flexed position. Excessively moving and crying child rarely has appendicitis. In a study by Chang et al., diagnosis could be made only after 2 or more visits in $15 \%$ of younger patients. Earlier visits were considered as nonspecific as the symptoms and signs were not specific ${ }^{14}$. If appendicitis progresses, localized abscess occurs in older children while diffuse peritonitis is common in infants. If the diagnosis is not clear in the absence of convincing findings, it is advisable to admit the child and subject the child to serial abdominal examinations. This policy does not increase the risks and decreases probability of false positives ${ }^{15}$.

\section{Complications}

Among all complications of appendicitis, perforation peritonitis remains important as it causes significant morbidity and mortality. Appendicular perforation is common in younger children (7.7\%) and increases with the duration of symptoms ${ }^{16}$. Rate of perforation is $80-100 \%$ in children less than 3 years as compared to $10-20 \%$ in children aged 1- 17 years $^{16}$. Fetal and infantile appendix is freely mobile and less likely to be fixed with caecum and other structure. Diffuse spillage occurs if appendix perforates ${ }^{2}$, and less amount of omentum also fails to localize the infection.

\section{Investigations}

Diagnosis of appendicitis is clinical. Laboratory and other imaging studies support our clinical suspicion. Total leucocyte count (TLC) is usually higher with Lymphocytosis because of non-specific conditions. So cut-off level is higher. Greater sensitivity and specificity of neutrophil/lymphocyte ratio (> 3.5) was found to be more sensitive/specific than TLC and neutrophil count alone ${ }^{17}$. Presence of high TLC and left shift has specificity of $94 \%^{18}$. Sensitivity and specificity of CRP is $57 \%$ and $87 \%$ in suspected appendicitis respectively ${ }^{19}$. Higher values are more significant in perforated appendicitis. Urine analysis is helpful to differentiate from urinary tract infection, urolithiasis or Henoch-Schonlein purpura.

Ultrasound of abdomen remains important investigation in case of doubt. A non-compressible, non-peristaltic, and greater than $6 \mathrm{~mm}$ tubular structure in right iliac fossa is suggestive of appendicitis. Secondary signs of appendicitis (hyperechoic mesenteric fat, fluid collection, localized dilated bowel loops) are equally important for diagnosis ${ }^{20}$.

CT scan has an accuracy of $97 \%$ for diagnosis ${ }^{21}$. The major disadvantage of CT scan is radiation exposure to child, and exposure to potentially hazardous contrast material. Properly done USG is equivalent to CT scan. Sensitivity, specificity and accuracy of 
non-enhanced CT is 97, 100, 98\% respectively, whereas sensitivity, specificity and accuracy of USG is $100,88,91 \%$ respectively ${ }^{21}$. These imaging methods are applied only if diagnosis is not clear. Pena et al. showed marked decrease in perforation and negative appendectomy by using CT and USG for suspected appendicitis ${ }^{22}$. There is no good evidence to support the routine use of CT $\operatorname{scan}^{23}$. Instead of this, clinical reevaluation and repeat USG is justified ${ }^{24}$.

On diagnostic confusion, serial examination of abdomen with or without serial USG monitoring can decrease the use of CT scan without increase in undue risk to the patient ${ }^{25}$. Because of concerns of radiation hazards, CT scan should be reserved as the last option. To overcome the hazardous effect of CT scan, MRI is gaining popularity. A recent study on MRI, showed high accuracy with sensitivity and specificity both $97 \%{ }^{26}$.

\section{Differential diagnosis}

Differential diagnoses of pain abdomen in children are numerous than in adults. Only $1-8 \%$ of children having pain abdomen have appendicitis ${ }^{12,27}$. Acute gastroenteritis is a common cause of pain abdomen in children. Typical features of pain abdomen, nausea and vomiting are same for gastroenteritis and appendicitis. It is mostly viral and self-limiting. Appendicitis may develop as complication of gastroenteritis due to obstruction of the lumen of appendix by enlarged lymphoid follicle.

Mesenteric lymphadenitis is a common differential diagnosis of acute appendicitis in children. Mostly, it is secondary to acute diarrhea and respiratory tract infection ${ }^{28}$. Clinical features are quite similar in both the conditions. Clinical evaluation alone may not be possible to differentiate acute mesenteric lymphadenitis from acute appendicitis ${ }^{29}$. Central or right sided pain abdomen, fever, nausea is present in mesenteric lymphadenitis but tenderness is not well localized. Pain may be severe but child is not prostrated. True abdominal rigidity is absent. Tenderness shifts while shifting the position ${ }^{30}$.

Ovarian pathology in female child is the most frequent differential of acute appendicitis. Common ovarian pathology in children include functional cysts, benign cysts, and malignant tumors. Clinical features are similar to acute appendicitis in right sided complicated ovarian cysts and tumors. In a study by Pomeranz et al., $38 \%$ of ovarian pathology had preliminary diagnosis of acute appendicitis ${ }^{31}$. Females had higher rate of misdiagnosis of acute appendicitis probably due to ovarian pathology 32 .

Constipation is a common problem. Abdomen pain may be associated with nausea and vomiting. Character of pain is not so severe. Acute constipation is usually associated with other acute pathology while chronic constipation is usually functional. Colonic fecal matter can be palpable abdominally of per rectally.

Other common differentials are acute pyelonephritis, urinary tract infection, abdominal trauma, intestinal obstruction, intestinal colic, right sided pneumonia and HSP. In case of diagnostic dilemma, a protocol of active monitoring admission to the hospital, and frequent abdominal examination preferably by the same surgeon with or without USG monitoring increases the diagnostic yield, without increase in undue risk to the patient ${ }^{25}$.

\section{Scoring system}

To make accurate diagnosis of appendicitis and avoid unnecessary negative appendectomies, different scoring systems have been designed. Alvarado is the first widely used system ${ }^{33}$. Originally it was designed for adults.

\section{Pediatric appendicitis sore (PAS)}

PAS is one of the modifications of Alvarado score for children ${ }^{34}$. It considers the physiological changes in children and clinical examinations that are suitable for them. Leucocytosis is scored as one point, tenderness 2 points. Samuel et al. and few others demonstrated increased accuracy in diagnosing appendicitis using PAS while others had failed to replicate those results. There was no difference between Alvarado score and PAS ${ }^{35}$.

\section{Kharbanda scoring system}

Kharbanda proposed a clinical rule based on a cohort of 601 pediatric patients ${ }^{36}$. It uses 6-part score that consists of nausea ( 2 points), focal right lower abdominal pain ( 2 points), migration of pain (1 point), difficulty walking (1 point), rebound tenderness/ pain with percussion ( 2 points), and absolute neutrophil count (ANC) $>6.75 * 10^{3} / \mathrm{uL}(6$ points). A score of 5 or less is considered as low risk for acute appendicitis. 


\section{Lintula score}

This score was described based on a cohort of 131 children aged 4-15 years ${ }^{37}$. The score uses 9 parameters (gender, fever, vomiting, pain at right lower abdomen, migration of pain, intensity of pain, guarding, rebound tenderness and bowel sound). Minimum score is 0 and maximum is 32 . Score less than 15 is grouped as low probable, 1621 as intermediate probable and more than 22 as high probable for acute appendicitis

\section{Management}

Once the diagnosis of acute appendicitis is made, emergency appendectomy is the treatment of choice. No delay in treatment should be done as risk of perforation increases with time. In the era of minimal invasive surgery, laparoscopic appendectomy in children is also gaining popularity. Initial literature demonstrated its safety profile and lower wound infection rates but it was not superior to open appendectomy. In a meta-analysis of randomized trials by Aziz et al. in 2006, there was no difference in wound infection rate - intra-abdominal abscess, post-operative ileus and post-operative fever $^{38}$. Operative time of laparoscopic method was not significantly longer and post-operative hospital stay was shorter. However, open appendectomy is still popular in current literatures. Alexander et al. observed that better outcome in younger children was obtained if operated by pediatric surgeon ${ }^{39}$.

Antibiotic administration is an important step for the initiation of treatment. Duration and choice of antibiotics may vary. Antibiotics only treatment is described in many literatures, past and recent. The risk of perforation and its consequences are the factors promoting the use of antibiotics in children. A randomized controlled trial was conducted by Svensson et al. comparing antibiotic versus surgery for acute non perforated appendicitis in children ${ }^{40}$. Success rate was $92 \%$ in antibiotic therapy and only $5 \%$ had recurrence on follow up. Recent literature suggests antibiotic only regimen in children is well tolerated and is efficacious in select population ${ }^{41}$.

\section{Interval appendectomy}

Role of interval appendectomy after treatment with antibiotics only regimen is a debatable issue. Recent literature is in favor of no interval appendectomy. Recurrence rate ranges from $0-20 \%{ }^{41}$. In a 4-year follow up study of 864 patients, Kaminski observed a recurrence rate of $5 \%$. It had milder clinical course than the first episode ${ }^{42}$. Higher recurrence rate $(77 \%)$ is seen if appendicolith is present during the first episode of appendicitis. Colonic cancers are more common after the age of 40 years. So, interval appendectomy is not routinely required unless risk factors like appendicolith and tumors are suspected. These studies are not confined to pediatric population. Appendicular lumen is mostly obstructed by enlarged lymphoid follicle than appendicolith in pediatric population. Colonic cancers are also not common in this age bracket. We can raise a question of routine use of interval appendectomy in children. However further studies are required to settle this debate.

\section{Conclusion}

Acute appendicitis in children is markedly different than in adults in many aspects. Small children tend to have more complicated appendicitis. History is less reliable in preverbal children making the clinical presentation more difficult. Clinical examination requires special skills. Almost every abdominal pathology can be confused with acute appendicitis, especially in children. There are few scoring systems designed to make diagnosis easy. Treatment remains the same as in adults.

\section{Disclosure}

None to declare

\section{References}

1. Addiss DG, Shaffer N, Fowler BS, Tauxe RV. The epidemiology of appendicitis and appendectomy in the United States. Am J Epidemiol. 1990;132(5):91025.

2. Almaramhy $\mathrm{HH}$. Acute appendicitis in young children less than 5 years: Revie article. Ital J Pediatr. 2017;43(1):15

3. Alder AC, Minkes RK, Cuffari C. Pediatric appendicitis. eMedicine from WebMD. 2018. Available from: https://emedicine.medscape.com/article/926795overview.

4. Karaman A, Çavuşoğlu YH, Karaman I, Cakmak O. Seven cases of neonatal appendicitis with a review of the English language literature of the last century. Pediatr Surg Int. 2003;19(11):707-9.

5. Bansal S, Banever GT, Karrer FM, Partrick DA. Appendicitis in children less than 5 years old: Influence of age on presentation and outcome. Am J Surg. 2012;204(6):1031-5. 
6. Mallick MS. Appendicitis in pre-school children: A continuing clinical challenge. A retrospective study. Int J Surg. 2008;6(5):371-3.

7. Walker AR, Segal I. What causes appendicitis? J Clin Gastroenterol. 1990;12(2):127-9.

8. Scammon R. The measurement of the body in childhood. The measurement of man. Minneapolis: University of Minnesota Press; 1930

9. Burkitt DP. The aetiology of appendicitis. British Journal of Surgery. Br J Surg. 1971;58(9):695-9.

10. Lin $\mathrm{YL}$, Lee $\mathrm{CH}$. Appendicitis in infancy. Pediatr Surg Int. 2003;19(1-2):1-3.

11. Rothrock SG, Pagane J. Acute appendicitis in children: Emergency department diagnosis and management. Ann Emerg Med. 2000;36(1):39-51.

12. Alloo J, Gerstle T, Shilyansky J, Ein SH. Appendicitis in children less than 3 years of age: A 28-year review. Pediatr Surg Int. 2004;19(12):777-9.

13. Becker T, Kharbanda A, Bachur R. Atypical clinical features of pediatric appendicitis. Academic emergency medicine. Acad Emerg Med. 2007;14(2):124-9.

14. Chang YJ, Chao HC, Kong MS, Hsia SH, Yan DC. Misdiagnosed acute appendicitis in children in the emergency department. Chang Gung Med J. 2010;33(5):551-7.

15. Surana R, O'Donell B, Puri P. Appendicitis diagnosed following active observation does not increase morbidity in children. Pediatr Surg Int. 1995;10:76-8.

16. Narsule CK, Kahle EJ, Kim DS, Anderson AC, Luks FI. Effect of delay in presentation on rate of perforation in children with appendicitis. Am J Emerg Med. 2011 Oct;29(8):890-3.

17. Goodman DA, Goodman CB, Monk JS. Use of the neutrophil:lymphocyte ratio in the diagnosis of appendicitis. Am Surg. 1995 Mar;61(3):257-9.

18. Wang LT, Prentiss KA, Simon JZ, Doody DP, Ryan DP. The use of white blood cell count and left shift in the diagnosis of appendicitis in children. Pediatr Emerg Care. 2007;23(2):69-76.

19. Yu CW, Juan LI, Wu MH, Shen CJ, Wu JY, Lee CC. Systematic review and meta-analysis of the diagnostic accuracy of procalcitonin, C-reactive protein and white blood cell count for suspected acute appendicitis. Br J Surg. 2013;100(3):322-9.

20. Wiersma F, Toorenvliet BR, Bloem JL, Allema JH, Holscher HC. US examination of the appendix in children with suspected appendicitis: The additional value of secondary signs. Eur Radiol. 2009;19(2):455-61.
21. Lowe LH, Penney MW, Stein SM, Heller RM, Neblett WW, Shyr Y, et al. Unenhanced limited CT of the abdomen in the diagnosis of appendicitis in children: Comparison with sonography. AJR Am J Roentgenol. 2001;176(1):31-5.

22. Peña BM, Taylor GA, Fishman SJ, Mandl KD. Effect of an imaging protocol on clinical outcomes among pediatric patients with appendicitis. Pediatrics. 2002;110(6):1088-93.

23. Martin AE, Vollman D, Adler B, Caniano DA. CT scans may not reduce the negative appendectomy rate in children. J Pediatr Surg. 2004;39(6):886-90.

24. Pastore V, Cocomazzi R, Basile A, Pastore M, Bartoli F. Limits and advantages of abdominal ultrasonography in children with acute appendicitis syndrome. Afr J Paediatr Surg. 2014 OctDec;11(4):293-6.

25. Russell WS, Schuh AM, Hill JG, Hebra A, Cina RA, Smith $C D$, et al. Clinical practice guidelines for pediatric appendicitis evaluation can decrease computed tomography utilization while maintaining diagnostic accuracy. Pediatr Emerg Care. 2013;29(5):568-73.

26. Kulaylat AN, Moore MM, Engbrecht BW, Brian JM, Khaku A, Hollenbeak CS, et al. An implemented MRI program to eliminate radiation from the evaluation of pediatric appendicitis. J Pediatr Surg. 2015 ;50(8):1359-63.

27. Caperell K, Pitetti R, Cross KP. Race and acute abdominal pain in a pediatric emergency department. Pediatrics. 2013;131(6):1098-106.

28. Sikorska-Wiśniewska G, Liberek A, Góra-Gebka M, Bako W, Marek A, Szlagatys-Sidorkiewicz A, et al. [Mesenteric lymphadenopathy - a valid health problem in children]. Med Wieku Rozwoj. 2006 AprJun;10(2):453-62. [Article in Polish]

29. Toorenvliet B, Vellekoop A, Bakker R, Wiersma F, Mertens B, Merkus J, et al. Clinical differentiation between acute appendicitis and acute mesenteric lymphadenitis in children. Eur J Pediatr Surg. 2011;21(2):120-3.

30. Helbling $R$, Conficconi $E$, Wyttenbach $M$, Benetti C, Simonetti GD, Bianchetti MG, et al. Acute nonspecific mesenteric lymphadenitis: more than "no need for surgery". Biomed Res Int, vol. 2017, Article ID 9784565.

31. Pomeranz AJ, Sabnis S. Misdiagnoses of ovarian masses in children and adolescents. Pediatric emergency care. Pediatr Emerg Care. 2004;20(3):172-4. 
32. Cheong LH, Emil S. Determinants of appendicitis outcomes in Canadian children. Journal of pediatric surgery. J Pediatr Surg. 2014;49(5):777-81.

33. Alvarado A. A practical score for the early diagnosis of acute appendicitis. Ann Emerg Med. 1986;15(5):557-64.

34. Samuel M. Pediatric appendicitis score. Journal of pediatric surgery J Pediatr Surg. 2002;37(6):877-81.

35. Pogorelic Z, Rak S, Mrklic I, Juric I. Prospective validation of Alvarado score and Pediatric Appendicitis Score for the diagnosis of acute appendicitis in children Pediatr Emerg Care. 2015;31(3):164-8.

36. Kharbanda AB, Taylor GA, Fishman SJ, Bachur RG. A clinical decision rule to identify children at low risk for appendicitis. Pediatrics. 2005;116(3):709-16.

37. Lintula $H$, Pesonen $E$, Kokki $H$, Vanamo K, Eskelinen M. A diagnostic score for children with suspected appendicitis Langenbecks Arch Surg. 2005;390(2):164-70.
38. Aziz O, Athanasiou T, Tekkis PP, Purkayastha S, Haddow J, Malinovski V, et al. Laparoscopic versus open appendectomy in children: A meta-analysis. Ann Surg. 2006;243(1):17-27.

39. Alexander F, Magnuson D, DiFiore J, Jirousek K, Secic $M$. Specialty versus generalist care of children with appendicitis: An outcome comparison. J Pediatr Surg. 2001;36(10):1510-3.

40. Svensson JF, Patkova B, Almström M, Naji H, Hall NJ, Eaton S, et al. Nonoperative treatment with antibiotics versus surgery for acute nonperforated appendicitis in children: A pilot randomized controlled trial. Ann Surg. 2015;261(1):67-71.

41. López JJ, Deans KJ, Minneci PC. Nonoperative management of appendicitis in children. Curr Opin Pediatr. 2017;29(3):358-362.

42. Kaminski A, Liu IL, Applebaum H, Lee SL, Haigh PI. Routine interval appendectomy is not justified after initial nonoperative treatment of acute appendicitis. Arch Surg. 2005;140(9):897-901. 